\title{
UNDERSTANDING GLOBAL CHANGE: A COGNITIVE PERSPECTIVE ON COMMUNICATING THROUGH
} STORIES

\author{
ANNE R. KEARNEY \\ School of Natural Resources and Environment, The University of Michigan, 430 E. University, \\ Dana Bldg., Ann Arbor, MI 48109-1115, U.S.A.
}

\begin{abstract}
Human behavior must be changed in order to ameliorate the adverse effects of global change. However, numerous studies have shown that durable change is difficult to achieve unless people have an adequate understanding of the problem and of appropriate behavioral solutions. Creating such an understanding has not been easy; the very nature of global change makes effective communication difficult. This paper proposes that one reason information has been unsuccessful is that it is not generally structured to take advantage of the way people process information. The cognitive processes involved in information acquisition and the special problems associated with communicating about global change are discussed. This discussion is used to identify those informational characteristics that will facilitate the transfer of information about global change. Stories (also referred to as case-studies or analogies) are suggested as one structure that encapsulates these characteristics; the role of stories in information transfer is elaborated upon. Though written from the point of view of presenting information to the public so that it creates understanding and impacts behavior, the paper is also relevant for scientists who wish to effectively communicate their ideas to the media and to researchers in other disciplines.
\end{abstract}

\section{Introduction}

Information aimed at encouraging conservation behavior and ameliorating environmental problems associated with global change has been largely ineffective. The typical informational approach to these issues that are highly abstract, happening on a huge scale, and can't be experienced directly has been to provide people with text that is highly abstract (e.g., providing scientific estimates of average expected temperature changes due to global warming), huge in scale (e.g., the number of species lost yearly, the number of forested acres lost daily), and is not directly related to daily experience (e.g., widening gaps in the ozone layer). Newspaper articles specializing in series of unrelated, vivid and concrete informational 'nuggets' (Graves et al., 1988) and a doom and gloom tone also fall far short of creating an understanding of the problems and offering potential solutions. We must do better than this.

There are two classes of solutions to increasing the effectiveness of text ${ }^{*}$ : one is to modify the reader's information processing (e.g. by requiring them to use

* Note that text is emphasized here because of its widespread use and relative inexpensiveness. The principles of effective information transfer, however, apply to other modes as well. 
outlining strategies or to take a test) so that they can glean more from existing text; the other is to modify text to fit more closely with the reader's biases in information processing (Resnick, 1984). The first class of solutions is impractical. Applying specific strategies to learn from less than optimal text is attentionally intensive; in a world where demands on our time and attention come from all quarters, there is little incentive to work so hard at learning. The only viable solution is to create texts that take advantage of the reader's natural processes and thereby facilitate learning.

A good story (case-study or analogy) is particularly compatible with the way people process information; it is one way to effectively communicate information about global change. Through stories, people can understand the meaning and scope of global changes and can gain suitable analogies for choosing appropriate actions (Halford and Sheehan, 1991). The potential of stories in communicating about global change and in promoting conservation behavior has largely been ignored; the urgency of these problems demands that it be explored.

This paper draws on cognitive theory to explore those textual characteristics that increase the transfer of information. First, an overview is given of the important role of knowledge in decision making and behavior change. Special attention is given to the difficulties in acquiring knowledge about global change. Next, the cognitive processes involved in information acquisition are described and some textual characteristics that facilitate information processing are discussed. Finally, it is pointed out that given the unique characteristics of global change issues and the constraints of human information processing, particular informational formats will be most effective at transmitting information. Stories, or analogies, are suggested as one such format.

\section{The Role of Information in Decision Making}

Effective communication about issues of global change is important on several fronts. First, given the interdisciplinary nature of global change, it is critical that scientists from disparate disciplines are able to communicate with one another. Second, decision makers rely on information from the scientific community to guide their decisions about policy, strategies, and priorities in issues of global change; to make effective decisions, they must understand the issues. Third, informational programs are part of many strategies aimed at encouraging people to change their behavior in order to reduce global scale environmental degradation. (e.g., There are governmental informational programs directed at affecting the purchase decisions of consumers; this information includes energy-efficiency labeling of autos and energy auditing programs (Yates and Aronson, 1984). Other informational programs are directed at changing daily behaviors such as commuting mode.)

Though few would argue against the importance of information, the problem of communicating - of transforming information to knowledge - is often disregarded. In many models of decision making, it is trivialized to the point that information 
is equated with understanding (e.g., see Yohe, 1991). These models assume that information need only be presented and that the individual who receives it will receive it as presented. The individual will then be able to combine the information with other information to arrive at some decision. In this model, the important informational variable is simply the amount of information the individual is given; the more information presented, the better the final decision will be. Such a model of knowledge acquisition and decision making is psychologically naive (Stern, 1992).

The acquisition of knowledge is not a straight-forward process. Because the human brain is a system with finite information processing resources operating in a world of infinite complexity, it is impossible to process and store everything. Humans are very selective about which stimuli they attend to and what information they remember. Information that is uninteresting, confusing, or seeminglyirrelevant will tend to be ignored altogether. It is also important to note that the information that does get processed by the brain is rarely stored as received. People bring their own knowledge, experiences, and biases to every new bit of information. Because of this, information is lost, warped, or even added during processing (Bartlett, 1932). This selectivity is one reason that the mere provision of information (e.g. pamphlets, slogans, instructions, uninspiring newspaper articles) has typically been ineffective at changing behavior (Ester and Winett, 1982; Stern and Aronson, 1984; Dennis et al., 1990). With information, what matters is not only how much is presented, but how it is conveyed (Stern, 1992).

Assuming the information is appropriately stored in the brain, it can then enter into the decision making process. Again, this process is not as straight-forward as it may appear. Specific bits of information are not the only components of the decision making process; the state of an individual's knowledge about the topic in question also plays an important role (Simon, 1992; see Kaplan, 1991, for a thorough discussion on this position). During decision making, an automatic assessment of how much knowledge an individual has and how solid that knowledge seems is made. This assessment is then combined with that person's actual knowledge about the issue, resulting in a decision.

The importance of this assessment of the state of an individual's knowledge cannot be overemphasized. People prefer making decisions that put them in situations where they can use what they know and where they feel they have sufficient knowledge to deal with unexpected events. Likewise, people dislike, and thus tend to avoid, decisions that would place them in situations where they have insufficient knowledge to guide their behavior and where the possibility of confusion is great. Thus, it is possible to see why people may choose not to adopt a behavior (e.g. recycle) when they feel they don't have enough information on what the behavior will entail. This may occur even though all the information they do have clearly makes adopting the behavior seem like the rational choice. In these cases, forcing someone to do a behavior (e.g. through the use of fines) may only reinforce the perception of having inadequate knowledge. In these cases, there can be consid- 
erable repercussions, including negative reactance (Reich and Robertson, 1979; Brahm and Brahm, 1981), a need to continually increase the external motivation, and a cessation of the behavior when the external motivation is stopped (Cook and Berrenberg, 1981).

The importance of knowledge (and the impact of a lack of knowledge) in the decision making process has been demonstrated in numerous studies. For example, a study of recyclers and non-recyclers (DeYoung, 1988) found no difference in attitudes or motives between the two groups, but a significant difference in knowledge. Confusion about the process of recycling was a strong predictor of non-recycling behavior. Others have shown that belief in a goal isn't enough to influence behavior; people must also have sufficient knowledge of appropriate behavior (Cook and Berrenberg, 1981; Weigel and Amsterdam, 1976). In a metaanalysis of 128 studies dealing with responsible environmental behavior Hines et al. (1986-87) explored the link between knowledge and behavior. They found that in those studies which included the measures, there was a positive correlation $(r=0.37, S D=0.202$ ) between knowledge (measured as knowledge of environmental issues and/or knowledge of how to take action on those issues) and behavior.

Without adequate knowledge an individual may not be confident enough to act (Ehrlich, 1969) or may not know how to achieve a goal (Levanthal, 1970). Confusion about a situation has been shown to have serious detrimental effects, causing people to give up on a problem (Halford and Sheehan, 1991) or show defensive avoidance of the issue (Janis and Mann, 1977).

\subsection{Informational Characteristics of Global Change Issues}

The state of an individual's knowledge about environmental issues and about appropriate behaviors for ameliorating environmental problems plays a large role in the decision making process. It follows that people must have an adequate understanding of global change issues if they are to be expected to respond with a change in behavior. Unfortunately, it appears that such an understanding is not widespread. Though researchers have only recently begun to explore nonexperts' understanding of global change, several recent studies have addressed the issue in relation to climate change. A nationwide survey (Research/Strategy/Management, Inc., 1989) found that $79 \%$ of those polled had heard of the 'greenhouse effect'; it seems that information is indeed reaching the public. Understanding the processes and consequences associated with the greenhouse effect, however, remains a challenge for many people. An in-depth study of lay people's conceptualization of global climate change (Kempton, 1991) found that lay people conceptualize both the processes of and behavioral solutions to climate change quite differently than do experts. The lay conceptualization of the processes of climate change was based on four categories: (1) stratospheric ozone depletion; (2) plant photosynthesis; (3) tropospheric pollution; and (4) personally experienced temperature variation. It 
is interesting to note that few of the subjects recognized the connection between energy consumption and global warming and that they typically regarded their personal fuel consumption as inelastic. In a prior study of Kempton et al. (1985), it was again shown that many people have a faulty conception about which behaviors have the greatest effect on energy use.

A recent study entitled 'The Joint Climate Project to Address Decision Makers' Uncertainties' (Bernabo and Eglington, 1993) suggests that this lack of understanding is not limited to lay people. In his presentation of the results of the study to the House Committee on Science, Space and Technology, Bernabo (1993) indicated that the need for cohesive mental models was identified as a priority by decision makers. He noted that decision makers need to understand the issues in terms of potential impacts rather than predictions of changing global mean values of climate variables. Apparently, even decision makers feel they are not receiving enough useful information about climate change.

One of the problems in communicating about global change lies in the selectivity of knowledge acquisition and the resultant difficulty in transferring information. Acquiring knowledge about global change is particularly difficult. With respect to the environment, much of people's understanding of the world and the way it works is based on experience; this model of the world tends to be maintained unless it is modified or contradicted by new experiences (Kaplan and Kaplan, 1982; Halford and Sheehan, 1991). Global change, then, is likely to be understood by most people only to the extent that it impacts their everyday life. The nature of global change, however, is such that it is virtually impossible to detect and experience. There are three major characteristics of global change that make it difficult to understand:

1. There is no experiential base for global change. Scientists say the Earth's temperature has increased by 0.5 degrees Fahrenheit in the last century and it is expected to continue rising (estimates range from 1.5 degrees to 4.5 degrees over the next 40 years) (Levy-Leboyer and Duron, 1991). This change is virtually impossible to perceive amidst daily, seasonal, and random temperature variations. Another reason that it is difficult to perceive human-caused global change directly is the gap between behavior and behavioral consequences. The time lapse between human activities and noticeable environmental effects is typically measured in years to decades and frequently extends beyond a single generation (e.g., as in the case of global warming) (Pawlik, 1991; Brewer, 1992; Halford and Sheehan, 1991).

2. Global change happens on a huge scale. Global changes affect entire natural systems, span continents and impact many populations. The very scale of these problems makes them hard to grasp and difficult to relate to everyday life. In light of these huge problems, individual behavior change can seem insignificant, causing people to feel helpless (Kaplan and Kaplan, 1982) and, hence, to avoid even thinking about the problem. 
3. Global change issues are inherently abstract. Understanding of abstract issues is built through repeated experience with the elements, or concepts, that are related to that issue (Kaplan and Kaplan, 1982). For example, nuclear war is a fairly abstract issue, but the concepts that relate to the issue (e.g., mushroom clouds, radiation poisoning, damage from a nuclear blast) are familiar to many people. Because of this, 'nuclear war' has a meaning for people that extends far beyond the mere meaning of the words. Another example of an abstract issue that is at least somewhat understandable is the economy (Halford and Sheehan, 1991). The economy doesn't exist as a concrete thing, but everyone has personal experience with economic effects; people pay interest rates, cringe at inflation, and see unemployment rising when the economy is in a slump. Global change is different. It may be easy to understand that the congestion on the highway is causing smog at a local level, but how does one think about an entire climatic system? What is carbon dioxide? What is ozone? They can't be smelled or seen and people generally don't perceive their impact as being as direct or significant as that of a nuclear blast or rising interest rates.

Because of these factors, it cannot be hoped that people will come to fully understand issues of global change in the course of their daily lives without help. The challenge is to design effective communication techniques that make salient an important and essentially abstract issue. An obvious choice is written information, or text. But as we have seen, not just any text will do. Many information-based programs fail because they never get the intended audience's attention, or because they get their audience's attention but don't present the information in a meaningful and understandable way (Dennis et al., 1990; Ester and Winett, 1982). The nature of global change issues (discussed above) provides some direction for designing effective communication techniques (i.e., the problems of lack of experiential base, abstraction, and scale must be dealt with). The next section will examine how people acquire knowledge and which informational characteristics facilitate this process. Understanding these cognitive processes will provide further constraints and direction for designing effective communication techniques.

\section{Cognitive Structure - A Theoretical Overview}

A basic argument in cognitive science is that individuals have mental models that serve as internal representations of the world. The position taken in this paper is that these models - cognitive maps - can be represented as networks of objects, or 'mental entities', that come to be linked through experience (Kaplan and Kaplan, 1982). ${ }^{*}$ The structure of these mental entities, called prototypes, and the linkages between them are discussed in more detail in the next section.

* Other models of knowledge organization (e.g., schemas, scenarios, and scripts) have been proposed yet lack physiological support. The cognitive map model has been accepted in fields as diverse as neuropsychology, psychology, and architecture (Downs and Stea, 1973; Alexander, 1965). 
What is a cognitive map? Take a moment to imagine the town in which you live. If you have been there for any length of time, you likely have a well-developed cognitive map of those areas in which you spend time. The prototypes, in this case, represent landmarks - your house, the building in which you work, a grove of evergreens, the park where you run, your neighbor's flower garden. The linkages between these prototypes represent the physical paths you take to get from place to place. If your structure is well-developed, you can think of many different routes to get from place to place, even if you've never actually taken one of those routes.

In contrast, imagine a city that you've been to only once or twice. In this case, you have a very weak cognitive map of the area; there are few landmarks you recognize and getting from one place to the next is difficult. In these situations, the chances of getting lost are quite high and most people don't relish exploring without some guidance. Notice the important role of an individual's state of knowledge in the decision making process. We tend to feel most comfortable in those areas for which we have a well-developed cognitive map. In contrast, we are often wary of those areas for which we have no, or at most a very weak, cognitive map. In the case of the latter, we may very well make a decision not to enter an area even if we were offered an external reward or were otherwise enticed.

The cognitive map model can be used equally well to describe the structure of information that is not purely physical (Siegel and White, 1975; Kaplan, 1976); in this case, the map consists of a group of associated prototypes that represent objects and concepts relating to a particular domain. For example, if you recycle regularly, you will have a well-developed map of the recycling process. The process is familiar to you, and you have a good sense of how all the objects and concepts that are relevant to recycling (e.g., plastic resins, cleaning out cans, waste reduction, curbside pickup) are related to each other (i.e., are linked together). For people without a cognitive map of the recycling process, thinking about recycling can be daunting. Just as we don't relish the prospect of roaming around a city for which we have no cognitive map, we are also reluctant to delve into situations for which we have no structure to guide our actions. In this case, not being sure how to recycle or what is expected of you may be enough to deter you from recycling even if there is a city ordinance (or some other incentive) to recycle.

\subsection{A More Detailed Analysis of Cognitive Structure}

Prototypes - the Basic Mental Entity. Things in the world come to be represented in the brain by groups of tightly interconnected neurons; these structures are called cell assemblies (Posner, 1986; Rosch, 1973) or prototypes. A prototype is an abstraction, or distillation of multiple experiences with a particular object or concept in the world (e.g., tree, deforestation, global warming); thus prototypes take numerous and varied experiences to create. Once prototypes are formed, they can be activated by something in the world (i.e., if an object has enough features in common with a particular prototype - or alternatively, enough of the most typical or salient features 
- then it will activate that prototype) resulting in 'recognition'. Prototypes can also be activated internally, allowing us to think about things that aren't present in the environment. The more experience we have with a particular object or concept, the more tightly connected the corresponding prototype becomes and the easier it is to activate.

Prototypes appear to be hierarchically arranged, with lower-level prototypes representing concrete things (e.g., your house, a tree, water) and higher level prototypes representing more abstract concepts (e.g., waste reduction, global warming, sustainable development) (Kaplan and Kaplan, 1982). At all levels, prototypes can be connected to modifiers such as language, ${ }^{*}$ color, spatial orientation, and affective codes (Kaplan and Kaplan, 1982).

Networking - Making Associations. Once a prototype has been formed, it can become linked, or associated, with other prototypes. These linkages are a reflection of experience; things that are related in the world (temporally, spatially, or conceptually) become associated in the mind. Activation spreads from prototype to prototype through these links, allowing the mind to go from one object or concept to the next - a 'train of thought'. In this way, we are able to make plans, run various scenarios in our head before taking action, and put individual objects and concepts into a larger context (Bruner, 1973). In short, cognitive maps are the means by which we model our world. This model, in turn, directs and constrains our thoughts, decisions, and actions.

\subsection{Cognitive Biases in Knowledge Acquisition}

Because an individual's cognitive maps are built from experience in a particular environment, we would expect great variability in the components of people's maps. The process of map construction (building prototypes and making linkages between prototypes), however, is universal; cognitive maps have been found in very young children and non-human primates as well as in human adults (Olton, 1979; Ratner and Myers, 1981). There are two important implications of these biases in knowledge acquisition and organization. The first is that unless new information is integrated into existing maps, it will be very difficult to access in the future. The nature of a cognitive map is such that activation can spread from one prototype to associated prototypes. In this way, the system has immediate access to concepts and thoughts that are related to the situation at hand. Information that is stored

* Though words and thoughts are often strongly related, they are not the same things (Ong, 1973); we know this intuitively from our own experience with forgetting a word but remembering the associated image, or visa versa. Several investigators have formally conceptualized the separation between verbal and imagistic thought in terms of separate yet interconnected systems (Paivio, 1978; Tulving, 1983). Though it is not entirely clear how this separation is manifested in the brain, evidence overwhelmingly supports the notion that language and thought are not synonymous (Furth, 1971). For example, numerous studies show a lack of interference between verbal and spatial tasks (see Reed, 1982 for an overview). If the processes were the same, we would expect one task to inhibit, or interfere, with the other (as is the case with two verbal or two spatial tasks). 
with few or no associations to existing prototypes is referred to as inert knowledge (Bereiter and Scardamalia, 1985, Schank, 1991) and cannot be activated in this way. The problem of inert knowledge has received much discussion in the science education literature. One recent study (Brown, 1992) explored the effect of textual information on high school students' ability to understand a physics problem. It was found that even after reading a text that contained the correct answer to the problem, the students reverted to their preconceptions to solve the problem. In this case, it is likely that information from the text, that didn't relate to the students' prior conceptions and did not draw upon familiar experiences, was stored in isolation. When confronted with the physics problem, this information was not activated and students relied on their familiar (and incorrect) models.

A second implication of the biases in knowledge acquisition and organization is that knowledge is constructed rather than received (Resnick, 1984); there is no simple correspondence between information presented and information stored. In education literature this is referred to as the constructivist theory of learning. It recognizes that the learner builds internal representations of new experiences in relation to past experiences. (For a more detailed discussion of this position and the support it receives from neurobiological theory, refer to Anderson, 1992.)

Because knowledge acquisition is not a trivial process and because we are bombarded by an almost infinite amount of information every day, we cannot possibly process and store all the information we encounter. A system of selective learning is necessary to guide us towards that information which is most important. Selectivity operates at two different phases of information processing: the first is perception (the activation of prototypes by the environment), the second is knowledge integration (making linkages between new information and existing maps). For example, in order to maximize learning from a text, the reader must first attend to the text (perception) and then, while reading, integrate the information in the text with existing knowledge (knowledge integration).

\subsection{Information Selection through Attention}

One of the most powerful mechanisms of selectivity in learning is attention. Attention is the means by which we are able to select and persist in processing particular information while ignoring other information. James (1892), distinguishes two types of attention: involuntary and voluntary (or directed) attention. Involuntary attention is based on interest; it is spontaneous and effortless and easily inhibits competing thoughts. Involuntary attention can either involve things of innate interest (James' list includes "strange things, moving things, wild animals, bright things, pretty things, metallic things, words, blows, blood, etc...") or be based on interests that have been gained through extended experience. Examples of learned interests include the interest an avid bird watcher takes in an unusual call or the interest of an expert chess player in a novel board configuration. The spontaneous nature 
of involuntary attention is quite adaptive as it assures that potentially important events and objects in the environment will be noticed without effort.

Directed (voluntary) attention is used to deal with numerous activities throughout the day that are necessary and important but that are intrinsically uninteresting (Cimprich, 1990). Invoking directed attention allows us to engage in purposeful, directed activity and thought. However, there is a cost associated with directed attention: it requires mental effort to sustain; it is neither spontaneous nor effortless and is thus subject to fatigue.*

Involuntary attention often falls under the general heading of interest. Information that we find interesting "elicits spontaneous rather than conscious, selective allocation of attention" (Hidi, 1990, p. 561). The role of interest in learning from text has received some attention (see Hidi and Baird, 1986; and Hidi, 1990, for excellent reviews). In general, interesting texts have been found not only to motivate people to read but also to increase comprehension of the text and to increase the likelihood that information in the text will be applied to novel situations. Drawing on involuntary attention is an effective strategy for increasing the probability that the reader will begin a text, learn the information contained in the text, and be able to use this information in the future. In this case, involuntary attention is acting on both stages of knowledge acquisition: activation of prototypes and knowledge integration. The section below provides a more detailed analysis of the characteristics of information that draw involuntary attention at each stage of knowledge acquisition.

\subsection{Indirection Attention and Knowledge Acquisition}

\subsubsection{Activating Prototypes}

Cognitive maps are accessed through the activation of prototypes. Once a prototype is active, a host of associated prototypes can potentially become active. In this way, new information becomes integrated into existing cognitive maps, giving it context and making it memorable. There are four major characteristics of text that aid in the activation of prototypes: content of the text, the degree to which it relates to the reader's prior knowledge, the concreteness of the text, and the use of vivid detail.

Content. As discussed earlier, attention can be involuntary drawn to text because of the text's specific content. Some themes draw on innate interest (e.g., death) and will be interesting to almost everyone. Other themes draw on learned interest (e.g., a text about the discovery of a new plant species may be very interesting to a botanist) and will vary among different cultural, age, and socio-economic groups.

* Directed attention appears to involve a different inhibitory mechanism than involuntary attention (Kaplan and Kaplan, 1982). The mechanism associated with directed attention is subject to fatigue through use while the inhibitory mechanism used in conjunction with involuntary attention is not. As the inhibitory mechanism fatigues, it becomes harder to keep out other thoughts, making directed attention difficult or impossible to sustain. 
The Role of Prior Knowledge. Only a prototype that exists can become active, ${ }^{* *}$ and the stronger a prototype is (i.e., the more familiar it is to the reader) the easier it will be to activate. The importance of 'knowing your audience' - of personalizing information so that it relates to the prior knowledge of a particular group - cannot be overemphasized. Anderson et al. (1987) suggested that 'character identification' and 'life themes' were important attributes of text that contribute to text-based interest. That is, they found that information was considered interesting if it had characters and themes with which the reader could identify. Other studies have shown that readers ignore or rework events and details that are unfamiliar. Bartlett (1932), presented a group of students with Native American folk tales. In general, the students forgot those events that seemed bizarre, reorganized sequences of actions to better fit their own expectations, and invented information to fit their own interpretations.

Concreteness. A short route to prototype activation in the absence of a physical environmental stimulus is through imagery. An image is, essentially, an active prototype (or group of prototypes) that represents something not present. The image can be formed through mental effort or it can be elicited by something in the environment (e.g., a word, a smell). The ease with which an image is formed is directly related to the ease with which a prototype is activated. In the case of written text, access to an individual's cognitive maps (i.e. prototype activation) can be achieved by choosing words that aid in imagery.

Paivio and Yuille (1969) argue that the concrete-abstract dimension is the most important determinant of the ease with which one can form an image (i.e., can activate a prototype). Concrete refers to a word or group of words that can be represented by a single image. The word 'clown' is concrete; most people cannot help conjure up an image when presented with this word. In contrast, abstract words (e.g. 'justice') stand for concepts that cannot be encapsulated within a single image. Paivio and Yuille (1969) presented pairs of words to subjects and found that imagery was reported for $62 \%$ of the concrete word-pairs and only $26 \%$ of the abstract wordpairs. Images for concrete words are often created spontaneously and effortlessly (pointing to the role of involuntary attention) while abstract words generally take longer to image, if they can be imaged at all (Clark and Paivio, 1987). Hidi and Baird (1988) showed that students tend to recall concrete, personally involving material better than generalized, abstract material, even when the abstract material was more important in expressing the main ideas of the passage.

A striking example of the importance of concrete information in understanding text comes from a study looking at how children solve word problems in mathematics (Hudson, 1983). The same problem was presented in two different forms:

\footnotetext{
** Of course it is possible to build prototypes from scratch, but this process can be difficult and time-consuming, (recall the roles of variability and multiple experiences in building a prototype). If an unfamiliar concept is introduced in the text, it may be remembered briefly, but it is unlikely that it will be retained.
} 
the first read, "There are 5 birds and 3 worms. How many more birds are there than worms?"; the second read, "There are 5 birds and 3 worms. How many birds won't get a worm?" The first problem was correctly solved by only $39 \%$ of the students while the second problem was correctly solved by $79 \%$. In this case, reading a problem involving a real-life situation that was easy to image made it much easier to form an appropriate model of the problem than did reading a problem with the abstract relational term 'more than'.

The importance of concrete information in decision making has also been widely explored (e.g., Nisbett and Ross, 1980; Nisbett et al., 1976). For example, Nisbett and Borgida (1975) found that when subjects were given abstract information about a group of people they were unwilling to apply this information when making predictions about the behavior of particular individuals. However, they were very willing to take concrete information about the behavior of two individuals to make predictions about the entire population. In this case, information from specific, concrete, cases was utilized in making decisions about future behavior, while abstract information was ignored. This occurred even though, in a statistical sense, the abstract information had more predictive power.

Vividness. While concrete refers to something that can be imaged, vivid can be defined in terms of the ease with which imagery occurs (Tulving et al., 1965). Superior recall is found for text that is concrete and contains vivid detail over text that is concrete but not vivid (Tulving et al., 1965). Vividness can be increased through the addition of detail (e.g. 'a storm' vs. 'a storm with a vicious wind and torrential rains'). Bower (1979) found that the rated vividness of a particular wordpair was predictive of the later recall of the pair; this effect was found even under incidental learning conditions, suggesting that in these situations, imaging occurred with no directed effort. Using vivid detail can also add power or importance to a message. A study on fear-arousing persuasive communication (Sherer and Rogers, 1984) showed that while concrete information significantly affected attitudes and increased recall, making the information more vivid by adding detail had a main effect not only on attitudes but on behavioral intent as well.

\subsection{Knowledge Integration}

Learning from text requires more than the activation of prototypes; a series of isolated facts or details do not create meaning. In fact, understanding and the ability to make generalizations from a text can be undermined by the provision of interesting but irrelevant detail (Garner et al., 1991). This means that it is not enough to entice the reader to the end of a text through the use of interesting detail; the information in the text must also be integrated with the reader's existing cognitive maps. This is necessary so that the information can be accessed in the future, combined with other information in new ways, and applied to novel situations (Garner et al., 1991; Schiefele, 1991). 
Knowledge integration requires making linkages, or associations among prototypes; this requires a certain level of involvement, or cognitive engagement on the part of the reader. Cognitive engagement refers to the process by which active prototypes are able to continually activate other, associated, prototypes that are pertinent to the issue or environment at hand. In this way, predictions can be made and compared to what occurs next in the environment. Cognitive engagement implies that competing thoughts are inhibited, allowing for a sustained train of thought. Involuntary attention plays a large role here. If the structure of the text is interesting (draws involuntary attention), it can direct thoughts and cause the reader to make associations while expending little mental effort. If the structure of the text is not interesting, the reader must invoke voluntary attention, purposively focusing on the flow of information and relating it to knowledge they already have. When using directed attention, the mental effort required to block out competing thoughts can be great and as soon as this effort is relaxed or as soon as fatigue sets in, the train of thought is interrupted. There is also often little incentive to continue a text that requires a great deal of mental effort.

Interesting stories are structured so that they are cognitively engaging, allowing for an effortless integration of new knowledge with existing cognitive structure. Sadoski et al. (1990) found that students who read an interesting short story not only formed powerful visual images from the text, but they also elaborated on and synthesized information in the text to the point that these elaborations were recalled as part of the original text. In this case, information from the story was being integrated with the readers' existing knowledge to form a map, or model, of the story. Interestingly, even students who were told to read the story for typographical errors (not for enjoyment or for recall) made these kinds of elaborations, supporting the notion that imaging and integration occur spontaneously and effortlessly when a text is interesting (Hidi, 1990). Interesting stories (as compared to stories of low interest) are also related to greater comprehension of the story's main ideas, greater ability to answer complex questions about the story, and greater ability to apply the information in the story to new situations (Schiefele, 1991; Bernstein, 1955). There are two major structural characteristics of text that aid in knowledge integration: the coherence of the text, and the presence of mystery in the text.*

Coherence. An analysis of stories by Stein and Glenn (1979) showed a striking linear relationship between the percentage of causally related events in the story and recall, showing that memorability of a story depends on causal cohesion among its events. In terms of cognitive engagement, if there is no cohesion or connection between the various elements making up a story, it is difficult to make associations between them and a train of thought cannot be created. The information must hang together sufficiently well so that the reader is able to see how the

* There is an implicit assumption that the reader has prior knowledge of generic social and causal relationships, and of potential outcomes which can be used in interpreting the text. 
various parts of the text relate (Kintsch, 1980). An incoherent text is unlikely to hold one's interest for long.

Coherence can be effectively achieved through a sense of movement, or direction through time (this need not be linear movement). In order to do this, the reader must be at least marginally aware of a goal state or valued endpoint (e.g., the destruction of something evil, victory over something, the discovery of something interesting or precious). Events in the text must then be arranged so that they relate in some gross way to the goal state (e.g., rendering it more or less probable) (Gergen and Gergen, 1986).

An Element of Mystery. Though a text needs to make sense, it shouldn't give everything away. Engagement is increased if the reader must predict and anticipate what will happen next (Kintsch, 1980; Schank, 1979). The presence of mystery, or uncertainty, causes the reader to generate a set of expectations (e.g., about what will happen next, about possible outcomes of the story, about motivations of the characters) against which future information can be matched. The reader is put in the position of wanting to know what will happen next, of searching for the very information that will be given in the proceeding text. When working optimally, this process will occur involuntarily and will wholly involve the brain in the text. As Dewey (1916, p. 126) writes, the "self and the world are engaged with each other in a developing situation."

In more specific terms, prediction and anticipation cause an active prototype to activate (or partially activate) several associated prototypes - these are the nominations, or expectations, for what is to come. Notice that these associated prototypes are part of the reader's existing cognitive maps; they are, in turn, associated with numerous other prototypes in the map. In this way, the information in the text becomes integrated into the map. When the map is accessed in the future, information from the text will become available.*

\section{Towards Effective Communication}

The nature of global change and the selectivity of knowledge acquisition give us useful direction and constraints in designing effective communication strategies. Specifically, in order to effectively communicate about issues of global change, text should: (1) address the characteristics of global change that make it difficult to communicate; and (2) be compatible with the processes of human knowledge acquisition. More specifically, the text must fulfill the following:

1. It must be interesting. With the plethora of information bombarding people everyday, it is understandable that much of it is ignored. We cannot assume that people will read what they are given. Because of this fierce competition for an

* The description here is quite abbreviated. The interested reader should consult Kaplan and Kaplan (1982) for a general overview of the concepts and Hidi (1990) for an overview of the process specifically as it relates to text processing. 
individual's attention, we must design information that draws on involuntary attention. Information must be able to 'hook' the reader, carry them through to the end of the text, and leave them with useful knowledge. As we have seen in the previous section, interesting content, coherence, a presence of mystery, and vivid detail are effective ways to increase interest.

2. It must present abstract information in such a way that the reader can imagine $i t$. Much of the information about global change is in the form of scientific data - highly abstract facts and figures that often have little impact on an individual's understanding of the issue. To promote understanding, information should be made concrete (e.g., through the use of specific examples) and vivid (through the use of detail).

3. It must relate to the reader's existing knowledge. New information that is wholly unrelated to the way people understand the world is likely to be ignored or, at best, stored as a chunk of inaccessible knowledge that is unlikely to be factored into everyday decisions and behavior. Information about global change must speak to the beliefs that people already hold about the environment; it must also relate to their daily experiences and address perceived obstacles to behavior change.

4. It must present global issues at a human scale. Information about large-scale events can be overwhelming. Telling examples come from the literature on natural disasters. In the face of large-scale disasters, people have a tendency to ignore information and warnings, leading them to deny the threat, refuse to leave an area, and return to the same site to rebuild (Burton et al., 1968; Watt, 1974). This behavior can be understood when we consider that thinking about something that you can't do anything about leads to a state of helplessness; this is a state that people actively avoid (Kaplan and Kaplan, 1982).

The current admonition to 'think globally, act locally' is a recognition that it is hard for people to feel they are making a contribution to a global problem (Bardwell, 1991). Bringing these global issues down to a human scale may be achieved through the use of characters or by highlighting local problems or behaviors that are related to global changes in the environment.

5. It must be extendible, to provide a large experiential base. One interesting and useful text is a good start, but in most cases it will not be enough. Recall that the prototypes that make up a cognitive map are built up slowly through repeated experience. Because building prototypes is a slow and conservative process, people generally need to be exposed to a number and variety of presentations of a particular concept or idea in order to generalize the information and apply it to new situations. Those prototypes which are the strongest (i.e., those corresponding to objects and ideas that are familiar - supported by numerous experiences - to an individual) will have a larger influence during decision making than will concepts that are less familiar (Tversky and Kahneman, 1982). 


\subsection{Communicating through Story}

A good story (note that story is broadly used here to include both fiction and non-fiction, case-studies, and some analogies) is one form of text that fulfills the above criteria. Stories have been proposed as effective tools for teaching and encouraging behavioral change (Monroe and Kaplan, 1988; Schank, 1991). They are inherently interesting, provide concrete examples of abstract issues or concepts, can be extended to provide multiple and varied 'experiences', can be crafted to relate to people's lives and what they already know, are inexpensive to create and distribute, and can be used across all age groups.

Stories have traditionally been used in all cultures to explain natural phenomena, convey morals and values, and guide appropriate behavior (Stein and Glenn, 1979; Bettelheim, 1976). Oral stories were often the only records of a culture passed down through generations. These tales were told with great care as they were recognized to be influential in the evolution of a given society (Baker and Greene, 1977).

Stories are still very much a part of the way we understand our world. Much of our daily communication is in the form of stories told and listened to (Schank, 1990b). A study of 'excellent companies' (Peters and Waterman, 1982) found that myths, stories, and legends appear to be very important in passing on and conveying the organization's shared values and culture. Stories have also been used by photocopy repairmen to diagnose problems with photocopiers; these stories are told and retold and become part of the knowledge base of the repairmen (Gudmundsdottir, 1991).

Stories have been particularly influential in decision making and education (Schank, 1990a; Halford and Sheehan, 1991). One study on the decision making process in government showed that people generally make decisions based on stories of incidents that had previously occurred and were similar to the situation at hand (Neustadt and May, 1986). Traditional midwives have been found to share stories to aid in diagnosis of problems and identify remedies (Gudmundsdottir, 1991). Monroe and Kaplan (1988) found that the use of case studies (stories) and talking about what others do to solve environmental problems may be more effective than 'learning by doing' for teaching environmental problem-solving skills. A later study of Monroe's (1991) showed a significant correlation between interesting stories and attitudes towards taking environmental actions. The impact of stories on behavior was directly shown by the effectiveness of an energy conservation tactic that made use of case-studies (stories) of 'super-conservers' (Yates and Aronson, 1983).

\subsubsection{Stories and Global Change}

Stories, especially story-like analogies, are widely used in formal science education and are often considered indispensable for providing students with the beginnings of understanding in unfamiliar domains (Thagard, 1991). The Journal of Chemical Education even runs a regular feature on 'Application and Analogies'. In one 
recent study (Brown, 1992), a story-like extended analogy was used to bridge the gap between students' preconceived notions of force and a Newtonian conception of force. The analogy specifically addressed the students' misconceptions and made use of concrete situations from their experience. After reading the analogy, students were much more likely to be able to correctly solve a variety of force problems than students who had read an excerpt from a text on the same subject.

Though most studies specifically on stories or analogies and global change are anecdotal rather than strictly empirical, there is sufficient evidence to suggest that they can increase people's understanding of global change processes and can provide imagery about the consequences of global environmental change (see Glantz, 1992 for an excellent review). Simple analogies (e.g., the greenhouse analogy) may be useful in conveying a single idea, while more complex, 'storylike' analogies may prove more useful in conveying an understanding of how global changes might impact the future.

Schneider takes this tact in creating plausible scenarios of the consequences of global changes. Several of these scenarios are included in his book Global Warming: Are We Entering the Greenhouse Century? (1990). The book begins with a chapter entitled 'Shadows of the Climate Future', an obviously fictitious account of what a year in the 'greenhouse century' might be like if nothing is done to deal with the growing problem of global warming. He writes:

"What happened that Sunday afternoon in Chicago actually originated over a thousand miles away in Saskatchewan, where a very intense three-week heat wave had come on the heels of a dry spring. Relative humidity had been abnormally low for the previous week. Then a cold front came through, triggering many relatively rainless thundershowers. From the lightning, fires broke out simultaneously over several thousand square miles. Within days, an area nearly the size of New Jersey had burned, and the drifting smoke was so thick over the Midwest that the late afternoon looked more like twilight for several days, including the Sunday afternoon when the second game of an important doubleheader was dimmed out of the record book.

Other climatic effects were far more serious than a called baseball game, however..." (p. 2).

Notice how the scenario has the effect of drawing the reader into the scene. The potential effects of climatic change are made real and imaginable, and the leading sentence at the end encourages the reader to continue. Contrast this with a rather dry description of a possible scenario printed in Nature:

"What would be the human (social, economic and political) impact of changes of the type presented here? We can only speculate on some of the possibilities - while noting that impact is at least as much related to the year-to-year variability of climate as it is to the mean or to changes in the mean. First, a substantial increase in the intensity of the Indian monsoon could have a significant impact. Although the impact of the monsoon in India is generally 
linked to its failure, increased and more violent precipitation can also have most detrimental effects (as witnessed by the flooding in 1979). Second, in some parts of the world (in particular in Europe and European Russia) temperature increase may occur in association with reductions in precipitation. These two factors will reinforce each other in increasing soil moisture deficits and so tend to have greater agricultural impact than either factor would alone. The climatic differences between warm and cold years which we have shown for Europe and European Russia appear to be of special importance as they indicate that conditions in a high- $\mathrm{CO}_{2}$ world could be radically different from those given by Kellogg for the Hypsithermal" (Wigley et al., 1980, pp. 20-21).

Notice the lack of specific examples of what the 'detrimental effects' and 'impacts' might be, the large-scale nature of the description, and the absence of interesting detail. For the non-expert reading this except, it would be very difficult to imagine and understand the scenario described. Unfortunately, much of the information presented by the scientific community and intended for the public, for decision makers, or for scientists in other disciplines is of this form. The contention of this paper is that this style of information presentation is not particularly effective at transferring information because it is not compatible with the way people process information.

A word of caution is necessary here. Though stories and analogies can be quite effective, they should not be used indiscriminately. Thagard (1992) discusses the pitfalls of using inappropriate analogies in education. In addition to the risk of creating a false understanding, the use of analogies or specific case studies can be misleading guides to action (Glantz, 1992). For instance, the careless use of historical analogies or the use of grossly untrue stories can lead to poor policy formation. Emphasis should be placed on stories as possible guides for action and not necessarily probabilistic forecasts.

This also underscores the need for numerous and varied analogies or stories relating to a particular topic or problem. A lone story will not likely impart the extent of knowledge and understanding necessary for sound decisions. Recall the process by which prototypes and cognitive maps are created. Multiple experiences not only strengthen individual prototypes but will create a more complex cognitive map. The resultant cognitive structure will be one that allows for exploration of ideas and for the discovery of several potential solutions to a problem.

\section{Conclusions}

Learning from text is greatly facilitated when the text is structured to take advantage of cognitive processes. Specifically, the effectiveness of text depends on activating pre-existing prototypes and integrating the information contained in the text into existing cognitive maps so that it becomes part of the readers 'real-world' knowledge. Textual characteristics that facilitate this process are: interesting content, relatedness to a reader's prior knowledge, concreteness, vividness, coherence, and 
mystery. These characteristics are perfectly encapsulated within a 'good story'. A prototypical story is organized into cohesive, thematic episodes that are causally related; it often contains a character, a predicament with an uncertain outcome, and resolution of the predicament (Stein and Policastro, 1984). Stories are generally of concrete things (though their overall meaning may be much more abstract), and are told with vivid detail.

Stories may be a particularly effective way to communicate about issues in global change; they can speak to people's lives and experiences the way no other text can. Stories are also able to put large-scale issues into a familiar context reducing "reality to a smaller scale that mimics it and yet enables us to deal with it in some manageable way" (Common, 1986).

It is no accident that stories have had such powerful influences on thought and behavior throughout history and throughout different cultures (Stein and Policastro, 1984). Stories can make the abstract concrete and accessible, turning what was only dimly perceived into something vivid and powerful. Stories put issues on a people-appropriate scale, filling one's head without overwhelming it with information. A good story is incorporated into the pre-existing cognitive structures representing what the reader already knows. In this way, their knowledge about the world is extended and, where necessary, corrected, with an ultimate effect on their beliefs and or how they might act in the future. Stories allow people to vicariously experience many different places, events, and situations; in this way they can prepare themselves in imagination for what life might bring and learn how to solve problems they have not yet experienced.

Though stories are particularly powerful tools for transferring information, they have not been widely used in education and behavioral change strategies. One possible reason is that stories and storytelling are associated with fantasy and pretending and thus may make the serious scientist or educator skeptical of their use, and, instead, favor the use of factsheets or textbooks. This reasoning has largely limited the use of stories in formal education to the primary level (Rosen, 1985). The urgency of global change problems, however, requires that we put preconceptions aside and utilize strategies that work with human nature rather than against it. Stories are one such strategy. A good story is particularly effective at transmitting information in a memorable and useful way because it is compatible with human information processes; the characteristics of a story take advantage of the way people process, store, and utilize information.

\section{Acknowledgements}

This research was performed under appointment to the Graduate Fellowships for Global Change Program administered by Oak Ridge Associated Universities for the U.S. Department of Energy, Office of Health and Environmental Research, Atmospheric and Climatic Research Division. 
I would like to thank Raymond DeYoung, Stephen Kaplan, and two anonymous reviewers for their very helpful comments on earlier drafts of this paper.

\section{References}

Alexander, c.: 1965, 'A City is not a Tree', Architec. Forum 122, p. 58.

Anderson, O. R.: 1992, 'Some Interrelationships between Constructivist Models of Learning and Current Neurobiological Theory, with Implications for Science Education', J. Res. Sci. Teaching 29 (10), 1037-1058.

Anderson, R. C., Shirey, L. L., Wilson, P. T., and Fielding, L. G.: 1987, 'Interestingness of Children's Reading Material', in Snow, R. E. and Farr, M. J. (eds.), Aptitude, Learning and Instruction: Vol. III. Cognitive and Affective Process Analyses, Lawrence Erlbaum Associates, Hillsdale, NJ, pp. 287-299.

Baker, A. and Greene, E.: 1977, Storytelling: Art and Technique, R. R. Bowker Co, New York.

Bardwell, L.: 1991, 'Success Stories: Imagery by Example', J. Environ. Educ. 23 (1), 5-10.

Bartlett, F. C.: 1932, Remembering, Cambridge University Press, Cambridge.

Bereiter, C. and Scardamalia, M.: 1985, 'Cognitive Coping Strategies and the Problem of "Inert Knowledge", in Chipman, S., Segal, J., and Glaser, R. (eds.), Thinking and Learning Skills: Research and Open Questions (Vol. 2), Lawrence Erlbaum Associates, Hillsdale, NJ.

Bernabo, J. C.: 1993, Statement Made before the House Committee on Science, Space and Technology, Hearing on Global Change Research: Science and Policy, 19 May, 1993.

Bernabo, J. C. and Eglington, P. D.: 1993, Joint Climate Project to Address Decision Makers' Uncertainties, Science and Policy Associates, Inc., Washington, D.C..

Bernstein, M. R.: 1955, 'Relationships between Interest and Reading Comprehension', J. Educ. Res. 49, 283-288.

Bettelheim, B.: 1976, The Uses of Enchantment: The Importance and Meaning of Fairy Tales, Alfred A. Knopf, Inc., New York.

Bower, G. H.: 1979, 'Mental Imagery and Associative Learning', in Gregg, L. (ed.), Cognition in Learning and Memory, Wiley, New York.

Brahm, S. and Brahm, J. W.: 1981, Psychological Reactance: A Theory of Freedom and Control, Academic Press, New York.

Brewer, G. D.: 1992, 'Environmental Challenges and Managerial Responses', in Choucri, N. (ed.), Global Commons: Environmental Challenges and International Responses, The MIT Press, Cambridge, Mass. (in press).

Brown, D. E.: 1992, 'Using Examples and Analogies to Remediate Misconceptions in Physics: Factors Influencing Conceptual Change', J. Res. Sci. Teach. 29 (1), 17-34.

Bruner, J. S.: 1973, 'Going beyond the Information Given', in Bruner, J. S. and Anglin, J. M. (eds.), Beyond the Information Given, Norton, New York.

Burton, I., Kates, R. W., and White, G. F.: 1968, 'The Human Ecology of Extreme Geophysical Events', Natural Hazard Working Paper No. 1, University of Toronto Press, Toronto.

Cimprich, B.: 1990, 'Attentional Fatigue and Restoration in Individuals with Cancer', Doctoral Dissertation, University of Michigan.

Clark, J. M. and Paivio, A.: 1987, 'A Dual Coding Perspective on Encoding Processes', in McDaniel, M. A. and Pressley, M. (eds.), Imagery and Related Mnemonic Processes: Theories, Individual Differences, and Applications, Springer-Verlag, New York, pp. 5-33.

Common, D. L.: 1986, 'Students, Stories, and the Social Studies', The Soc. Stud., November/December, 246-48.

Cook, S. and Berrenberg, J.: 1981, 'Approaches to Encouraging Conservation Behavior: A Review and Conceptual Framework', J. Soc. Issues 37 (2), 73-107. Costanzo, M., Archer, D., Aronson, E., and Pettigrew, T.: 1986, 'Energy Conservation Behavior: The Difficult Path from Information to Action', Amer. Psychol. 41, 521-28.

Dennis, M., Soderstrom, E., Koncinski, W., Cavanaugh, B.: 1990, 'Effective Dissemination of Energy Related Information: Applying Social Psychology and Evaluative Research', Amer. Psychol. 45(10), 1109-1117. 
Dewey, J.: 1916, Democracy and Education: An Introduction to the Philosophy of Education, Macmillan, New York.

DeYoung, R.: 1988-1989, 'Exploring the Differences between Recyclers and Non-Recyclers: The Role of Information', J. Environ. Syst. 18 (4), 341-351.

Downs, R. and Stea, D.: 1973, 'Cognitive Maps and Spatial Behavior: Processes and Products', in Downs, R. and Stea, D. (eds.), Image and Environment, Aldine, Chicago.

Ehrlich, H.: 1969, 'Attitudes, Behavior and the Intervening Variables', Amer. Sociol. 4, 29-34.

Ester, P. and Winnett, R.: 1981-82, 'Towards More Effective Antecedent Strategies for Environmental Programs', J. Environ. Syst. 11 (3), 201-221.

Furth, H. G.: 1971, 'Linguistic Deficiency and Thinking, Research with Deaf Subjects, 1964-1969', Psychol. Bull. 76, 58-72.

Garner, R., Alexander, R. A., Gillingham, M. G., Kulikowich, J. M., and Brown, R.: 1991, 'Interest and Learning from Text', Amer. Educ. Res. J. $28(3), 643-659$.

Gergen, K. J. and Gergen, M. M.: 1986, 'Narrative Form and the Construction of Psychological Science', in Sarbin, T. R. (ed.), Narrative Psychology: The Storied Nature of Human Conduct, Prager, New York, pp. 22-44.

Glantz, M. H.: 1992, 'The Use of Analogies in Assessing Physical and Societal Responses to Global Warming', Environment 34 (5).

Graves, M. F., Slater, W. G., Roen, D., Redd-Boyd, T., Duin, A. G., Furniss, D. W., Hazeltine, P.: 1988, 'Some Characteristics of Memorable Expository Writing: Effects of Revisions by Writers with Different Backgrounds', Res. Teach. Engl. 22, 242-265.

Gudmundsdottir, S.: 1991, 'Narratives and Cultural Transmission in Home and School Settings', Paper presented at the Annual Meeting of the American Educational Research Association, Chicago.

Halford, G. S. and Sheehan, P. W.: 1991, 'Human Response to Environmental Changes', Int. J. Psychol. 26 (5), 599-611.

Hidi, S.: 1990, 'Interest and Its Contribution as a Mental Resources for Learning', Rev. Educ. Res. $60(4), 549-571$.

Hidi, S. and Baird, W.: 1986, 'Interestingness - A Neglected Variable in Discourse Processing', Cognitive Sci. 10, 179-194.

Hidi, S. and Baird, W.: 1988, 'Strategies for Increasing Text-Based Interest and Students' Recall of Expository Texts', Read. Res. Quart. 23, 465-483.

Hines, J. M., Hungerford, H. R., Tomera, A. N.: 1986-87, 'Analysis and Synthesis of Research on Responsible Environmental Behavior: A Meta-Analysis', J. Environ. Educ. 18 (2), 1-8.

Hudson, T.: 1983, 'Correspondences and Numerical Differences between Disjoint Sets', Child Develop. 54, 84-90.

James, W.: 1892, Psychology: The Briefer Course, Collier Book, New York, 1962.

Janis, I. and Mann, L.: 1977, Decision Making, Free Press, New York.

Kaplan, S.: 1976, 'Adaptation, Structure, and Knowledge', in Moore, G. and Golledge, R. (eds.), Environmental Knowing, Dowden, Hutchinson and Ross, Strondsberg, PA.

Kaplan, S.: 1991, 'Beyond Rationality: Clarity-Based Decision Making', in Garling, T. and Evans, G. (eds.), Environment, Cognition, and Action, Oxford University Press, New York, pp. 171-190.

Kaplan, S. and Kaplan, R.: 1982, Cognition and Environment: Functioning in an Uncertain World, Ulrich's, Ann Arbor, Michigan.

Katzev, R. D.: 1989, 'How to Motivate Recycling: Applying Minimal Justification Techniques', Paper presented at The Association for Conservation Information's Winter Workshop, Arlington, VA, (February).

Katzev, R. D. and Pardini, A. V.: 1987-1988, 'The Comparative Effectiveness of Rewards and Commitment Approaches in Motivating Community Recycling', J. Environ. Syst. 17, 93-113.

Kempton, W.: 1991, 'Lay Perspectives on Global Climate Change', Glob. Environ. Change 1, 183208.

Kempton, W., Harris, C. K., Keith, J. G., Weihl, J. S.: 1985, 'Do Consumers Know What Works in Energy Conservation?', Marriage Fam. R. 9, 115-133.

Kintsch, W.: 1980, 'Learning from Text, Levels of Comprehension, or: Why Anyone Would Read a Story Anyway', Poetics 9, 87-98. 
Levanthal, H.: 1970, 'Findings and Theory in the Study of Fear Communication', in Berkowitz, L. (ed.), Advances in Experimental Social Psychology: Vol. V., Academic Press, New York.

Levy-Leboyer, C. and Duron, Y.: 1991, 'Global Change: New Challenges for Psychology', Int. J. Psychol. 26 (5), 575-583.

Monroe, M.: 1991, 'The Effect of Interesting Environmental Stories on Knowledge and Action-Taking Attitudes', Doctoral Dissertation, University of Michigan.

Monroe, M. and Kaplan, S.: 1988, 'When Words Speak Louder than Actions: Environmental Problem Solving in the Classroom', J. Environ. Educ. 19 (3), 38-41.

Nisbett, R. E. and Borgida, E.: 1975, 'Attribution and the Psychology of Prediction', J. Personal. Soc. Psychol. 32 (5), 932-943.

Nisbett, R. E. and Ross, L.: 1980, Human Inferences: Strategies and Shortcomings of Social Judgment, Prentice-Hall, Inc., Englewood Cliffs, NJ.

Nisbett, R. E., Borgida, E., Crandall, R., Reed, H.: 1976, 'Popular Induction: Information is Not Necessarily Informative', in Carroll, J. S. and Payne, J. W. (eds.), Cognition and Social Behavior, Lawrence Erlbaum Associates, Hillsdale, New Jersey, pp. 113-133.

Neustadt, R, and May, E.: 1986, Thinking in Time: The Uses of History for Decision-Makers, Free Press, New York.

Olton, D. S.: 1979, 'Mazes, maps, and memory', Amer. Psychol. 34, 583-596.

Ong, W. J.: 1973, A Conversation about Language with Walter J. Ong Conducted by Wayne Altree, Chandler and Sharp Publishers, Inc., San Francisco.

Paivio, A.: 1978, 'Dual Coding: Theoretical Issues and Empirical Evidence', in Scandura, J. M. and Brained, C. J. (eds.), Structural/process Models of Complex Human Behavior, Nordhoff, Leiden, The Netherlands.

Paivio, A. and Yuille, J. C.: 1969, 'Changes in Associative Strategies and Paired-Associate Learning Trials as a Function of Word Imagery and Type of Learning Set', J. Exp. Psychol. 79, 458-463.

Pawlik, D.: 1991, 'The Psychology of Global Environmental Change: Some Basic Data and an Agenda for Cooperative International Research', Int. J. Psychol. 25(5), 547-563.

Peters, T. J. and Waterman, R. H.: 1982, In Search of Excellence: Lessons from America's Best Run Companies, Harper and Row, New York.

Posner, M.: 1986, 'Empirical Studies of Prototypes', in Crain, C. (ed.), Noun Classes and Categorization, John Benjamins, Philadelphia.

Ratner, H. H. and Myers, N. A.: 1981, 'Long-Term Memory and Retrieval at Ages 2, 3, 4', J. Exp. Child Psychol. 31, 365-386.

Reed, S. K.: 1982, Cognition: Theory and Applications, Brooks/Cole, Monterey, CA.

Reich, J. W. and Robertson, J. L.: 1979, 'Reactance and Norm Appeal in Antilittering Messages', $J$. Appl. Soc. Psychol. 9, 91-101.

Research/Strategy/Management, Inc.: 1989, Global Warming and Energy Priorities: A National Perspective, Commissioned by the Union of Concerned Scientists, Cambridge, MA, November.

Resnick, L. B.: 1983, 'Mathematics and Science Learning: A New Conception', Science 220, 477478.

Resnick, L. B.: 1984, 'Comprehending and Learning: Implication for a Cognitive Theory of Instruction', in Mandl, H., Stein, N. L., Trabasso, T. (eds.), Learning and Comprehension of Text, Lawrence Erlbaum Associates, Hillsdale, NJ.

Rosch, C.: 1973, 'Natural Categories', Cog. Psychol. 4, 328-350.

Rosen, H.: 1985, Stories and Meaning, David Green Printers, Ltd., Northamptonshire, England.

Sadoski, M., Goetz, E. T., Olivarez, A., Lee, S., Roberts, N. M.: 1990, 'Imagination in Story Reading: The Role of Imagery, Verbal Recall, Story Analysis, and Processing Levels', J. Read. Behav. $22(1), 55-70$.

Schank, R. C.: 1979, 'Interestingness: Controlling Inferences', Artif. Intell. 12, 273-297.

Schank, R.: 1990a, A Role for AI in Education: Using Technology to Reshape Education, Technical Report @ 1, Institute for Learning Sciences, Northwestern University, Evanston, IL.

Schank, R.: 1990b, Tell Me a Story: A New Look at Real and Artificial Memory, Scribner, New York.

Schank, R.: 1991, Case-Based Teaching: Four Experiences in Educational Software Design, Technical Report @7, Institute for Learning Sciences, Northwestern University, Evanston, IL.

Schiefele, U.: 1991, 'Interest, Learning, and Motivation', Educ. Psychol. 26 (3 and 4), 299-323. 
Schneider, S. H.: 1990, Global Warming: Are We Entering the Greenhouse Century? Sierra Club, San Francisco.

Sherer, M. and Rogers, R. W.: 1984, 'The Role of Vivid Information in Fear Appeals and Attitude Change', J. Res. Personal. 18, 321-334.

Siegel, A. W. and White, S. H.: 1975, 'The Development of Spatial Representations of Large-Scale Environments', Advan. Child. Develop. Behav. 10, 9-55.

Simon, H. A.: 1992, 'What is an "explanation" of behavior?', Psychol. Sci. 3 (3), 150-161.

Stein, N. L. and Glenn, C. G.: 1979, 'An Analysis of Story Comprehension in Elementary School Children', in Freedle, R. O. (ed.), New Directions in Discourse Processing, Lawrence Erlbaum Associates, Hillsdale, NJ.

Stein, N. L. and Policastro, M.: 1984, 'The Concept of Story: A Comparison between Children's and Teachers' Viewpoints', in Mandl, H., Stein, N. L., Trabasso, T. (eds.), Learning and Comprehension of Text, Lawrence Erlbaum Associates, Hillsdale, NJ.

Stern, P. C.: 1992, 'What Psychology Knows about Energy Conservation', Amer. Psychol. 47 (10), $1224-1232$.

Stern, P. C. and Aronson, E. (eds.): 1984, Energy Use: The Human Dimension, Freeman, New York.

Thagard, P.: 1992, 'Analogy, Explanation, and Education', J. Res. Sci. Teach. 29 (6), 537-544.

Tulving, E.: 1983, Elements of Episodic Memory, Oxford University Press, New York.

Tulving, E., McNulty, J. A., Ozier, M.: 1965, 'Vividness of Words and Learning to Learn in FreeRecall Learning', Can J. Psychol. 19, 242-252.

Tversky, A. and Kahneman, D.: 1982, 'Judgment under Uncertainty: Heuristic and Biases', in Kahneman, D., Slovic, P., and Tversky, A. (eds.), Judgment under Uncertainty: Heuristic and Biases, Cambridge University Press, New York.

Vargish, T.: 1980, 'Why the Person Sitting Next to You Hates Limits to Growth', Technol. Forecast. Soc. Change 16, 179-189.

Watt, K. E. F.: 1974, The Titanic Effect, Sinauer, Stamford, Conn.

Weigel, R. and Amsterdam, J.: 1976, 'The Effects of Behavior Relevant Information of AttitudeBehavior Consistency', J. Soc. Psychol. 98, 247-251.

Wigley, T. L., Jones, P. D., Kelly, P. M.: 1980, 'Scenario for a Warm, High-CO ${ }_{2}$ World', Nature 283, $17-21$

Yates, S. and Aronson, E.: 1983, 'A Social-Psychological Perspective on Energy Conservation in Residential Buildings', Amer. Psychol. 38, 435-444.

Yohe, G. W.: 1991, 'Uncertainty, Climate Change and the Economic Value of Information', Policy Sci. 24, 245-269.

(Received 5 April, 1993; in revised form 18 February, 1994) 